\title{
The comparison of complexities of the Chinese and Russian languages on the example of terminology of chemistry
}

\author{
Zhanna K. Ivanova ${ }^{1, *}$, Juri V. Kobenko ${ }^{2}$, Mariya A. Kulkova ${ }^{3}$, and Elena S. Riabova ${ }^{4}$ \\ ${ }^{1}$ National Research Tomsk Polytechnic University, 634050 Tomsk, Russia \\ ${ }^{2}$ National Research Tomsk State University, 634050 Tomsk, Russia \\ ${ }^{3}$ Kazan Federal University, 420008 Kazan, Russia \\ ${ }^{4}$ Samara University, 443086 Samara, Russia
}

\begin{abstract}
The article presents the examples of comparing chemical terms in the Chinese and Russian languages and the results of two experiments conducted with Chinese and Russian students. The first part of the work deals with a comparison of the one-component chemical element names from the periodic table. Then, it continues with dividing different chemical terms in Chinese into several groups: two-component, three-component, four-component, multicomponent group and comparing them with its analogical terms in Russian to analyze the main difficulties in understanding these terms in both languages. The second part of the work presents the main difficulties, revealed during two experiments, conducted with Chinese and Russian students. The students were given texts in their mother tongues with a chemical context, which they wrote and read noting the time. At the end of the work, all the advantages and complexities revealed in the results of the first and second parts of the work were calculated. Similar language comparisons are becoming more relevant in the last few years, for they contribute to development of methods of analyzing languages and discovering new and improved approaches to the study and use of languages.
\end{abstract}

\section{Introduction}

Many linguists are wondering whether it is possible to assess the complexity of languages objectively, that is, without attracting native speakers of a particular language. If so, what criteria should be chosen. A. Piperski gives an example of a situation when the Martian has flown to our planet and needs to learn the human language - which language would be easier for him, and which would be more difficult [1]. Linguists studying language complexity are trying to answer this question.

This science field is relatively young, its active development began only in the last 20 25 years and therefore it still does not have a universal theory and methods of verification. Nevertheless, the science of language complexity has already managed to make three main theoretical conclusions, which A. Berdichevsky summarized in his work: 1. The widespread

* Corresponding author: ivanova.happy@yandex.ru 
idea that all languages are equally complex is incorrect. 2. You can not only rank languages by complexity, but also try to measure the complexity of a language - or at least a fragment of a language - quantitatively. 3. Quantitative measurements, as well as some qualitative studies show that the complexity of the language depends on social parameters. [2].

In the Chinese and Russian languages most of the terminology consists of borrowing primarily from the English language. Each of these languages has its own ways of borrowing and translating Western terms, which are unique in their own way and have both positive and negative sides.

In the Chinese language most of the borrowings refer to a group of semantic borrowings, while phonetic borrowings are less represented. The main way of forming a term is composition as the most productive way of replenishing the Chinese terminology of material science.

In the Russian language, unlike the Chinese, borrowing from the English language, indirect borrowing, or borrowing in parallel with analogues in the Russian language prevail. These types of borrowings are good in terms of the terminology internationalization and the cumulative function of the English language, but are difficult for understanding by the speakers of the recipient language. Of course, the use of such terms is not a problem when a person knows the Latin and Greek languages, and nowadays even the knowledge of English is enough. However, a foreign language with respect to the Russian language is an external knowledge (meta-knowledge), the volume of which should be minimized.

\section{The results of the comparison of the Russian and Chinese languages}

As the result of the analysis of chemical elements terms in the Chinese and Russian languages, the main conclusion was made in the context of the two different systems of borrowings of the chemical element terms in the periodic table - this is the advantage of the Chinese terms over the Russian ones, which consists in the translation systematicity of Chinese terms from the original language with the help of the keys. Moreover, while analyzing single-component names of 118 chemical elements of the D.I. Mendeleev's table in the Chinese language the following features were revealed:

- all elements have a key denoting the category of the element that helps to achieve systematicity in translating borrowings of these terms. For example, all the metals have the key 兴 “metal” (钠 - sodium, 钾 - potassium, etc.), nonmetals - keys石 “stone” (硫 - sulfur,

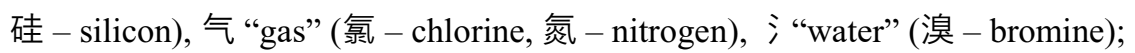

- out of 118 terms, 95 characters have a key "metal", 10 - "stone", 12 - "gas", 2 "water";

- 11 names of chemical elements reflect certain properties or characteristics of these elements, for example, 溴xiù "bromine" from Greek $\beta \rho \tilde{\omega} \mu \varsigma_{\varsigma}$ is a "stench"" because the simple substance bromine is a heavy caustic liquid with a strong unpleasant "heavy" smell, and this property is reflected in the meaning of the often used in everyday speech hieroglyph 臭xiù “stinky, rotten", which is used in the right part of the term;

- in the remaining 107 terms, the hieroglyphs used in the right part do not reflect any properties of these elements, performing only the function of phonetics in the terms.

Unlike Chinese terms there is no systematicity in Russian naming units that consists of "hints" or category designations of chemical elements. The only common element in Russian naming units is similar suffixes at the end of the terms. For example, in 65 names of metals out of 96 ones there is a suffix of masculine gender $-\mathrm{i}$ at the end of the term. Therefore, almost $68 \%$ of the names of metals are systematized to some extent. However, some 
nonmetals also have the suffix $-\mathrm{i}$ kremni (silicon), geli (helium), which confirms the ineffectiveness of suffixes as a possible method of chemical names systematizing. Further, the chemical terms of the Chinese language, which include more than one hieroglyph, are analyzed. The results of the analysis show the transparent semantics of Chinese terms, which clearly reflects the meaning of the term and promotes the understanding of terms by native speakers. Russian terms in comparison with Chinese ones are less clear since most terms are borrowed from the ancient Greek and Latin languages. Let us give some examples.

Two-component term 加嗅 “odorization”: add + smell. In the dictionary, the term "odorization" is defined as giving (to the gas) a characteristic odor. As it can be seen, the translation of the term hieroglyphs ideally reflects the essence of the term.

Three-component term 催化剂 “catalyst" is a chemical that accelerates the reaction. This word comes from the Greek katalysis - destruction. In Chinese the hieroglyphs in this term mean "hurry, induce + chemical + substance, means" - the meaning of the hieroglyphs clearly describes the term.

Four-component term 两性 离子 “amphion” or otherwise "amphoteric ion”. In this phrase, the most unclear word is amphoteric, which comes from the Greek word "amphotero" - "dual", "reciprocal" In the Chinese term, hieroglyphs consistently mean: "two + quality, property, suffix -ost + part, leave + particle." We see that the first two hieroglyphs clearly denote the concept of "duality", since amphotericity is the ability of certain chemicals and compounds to have both acidic and basic properties depending on the conditions. The answer to the question, why the term "ion" has the hieroglyph 离 "to part, to leave" is also quite simple - since an ion is produced in the process of separation or addition of an electron to an atom or group of atoms.

Multicomponent term 非压缩氢气 “uncompressed hydrogen”. Let us analyze the components of this term: no + pressure + compress + hydrogen + gas. In the Russian version of this term we come across a word of Latin origin "compression", which means "limit the amount of gas under the influence of external forces in order to reduce its volume, increase of pressure and temperature.

\subsection{The results of the first experiment}

During the first experiment with the writing, the following Chinese language difficulties that Chinese students experienced were revealed.

1. Comparatively long average time of a small text writing - a little more than half a page in $19 \mathrm{~min} .6 \mathrm{sec}$.

2. The problem with punctuation and paragraph indention that makes the text look unstructured.

3. The big difference between classical written and spoken Chinese.

4. The difficulty of hieroglyphs spelling - native speakers forget how to write some hieroglyphs or certain parts of hieroglyphs. For example, students forgot how to write 醛 quán (aldehyde) and 粪 fèn (manure).

5. Homonymy of the Chinese language - because of the consonance of the words hieroglyphs that were not in the text were written. For example, 攝入 shè rù (absorption) 涉 入 shè rù (penetrate).

6. The confusion of words, which partly sound the same and are partly similar in spelling. For example, 非 fêi (not-) and 没 méi (not).

7. Words are not separated from each other by spaces in the written form, as in Russian, thus, it is sometimes visually difficult to determine the boundaries of words. 
Difficulties of the Russian language, which Russian students experienced during the first experiment.

1. Complexity of grammatical forms that makes it easy to confuse letters in endings, roots or suffixes of words, even simply by inattention. For example, some students wrote "YestestvennYJ and naturalnYJE flavors" (Natural (singular form) and natural (plural form) flavors).

2. Fast fatigue while writing full words without abbreviations.

3. Voiceless/voiced letters at the end of the word - the need to check the spelling of words by changing the form of the word, or simply memorizing the rules. For example, students wrote CinnamaldegiT, instead of CinnamaldegiD.

4. A large number of words of Latin and Greek origin (aromatizator, cinnamaldegide, vanillin, orchideya, glutamat natria, etc.).

The advantages of the Chinese language, revealed during the first experiment:

5. A comparatively small amount of text that takes up less space on the paper.

6. Borrowed words with transparent semantics, which makes terms more understandable in writing. For example, the Chinese word 香草 “scented grass," means "vanilla”, but in Russian this word is borrowed, or, for example, the word 香精 “fragrant extract”, which is translated into Russian by the Latin word "aromatizator".

The advantages of the Russian language, found out during the first experiment:

1. Comparatively high average speed of text writing $-20 \mathrm{~min}$. $6 \mathrm{sec}$., especially with the reduction of words $-15 \mathrm{~min} .30 \mathrm{sec}$.

2. The presence of grammatical forms allows you to get more information, which contributes to more detailed understanding and translation. For example, the verb "pridumala" (invent): first, we immediately see that the subject of the action is a woman (feminine gender); secondly, we know for sure that the subject is one (singular), thirdly, the action was in the past ( the past tense), fourthly, the action did not take place for a certain period of time, but was completed at a certain stage (the perfect aspect of the verb). In the Chinese translation “发明” there are not such informative grammatical categories.

3. In Russian it is impossible to forget how the whole word is written, you can only make a mistake in writing a letter or a syllable (in Chinese you can forget how to write the whole hieroglyph or confuse and write another hieroglyph that sound the same).

4. A more sophisticated system of punctuation (in Russian it was easier to indent paragraphs and place commas).

\subsection{The results of the second experiment}

The difficulties of the Chinese language that were revealed during the second experiment with oral speech.

1. One character can be read in different ways and there are no clear rules for this or that variant of reading, you can check only in the dictionary. For example, in the hieroglyph 差, in addition to reading chā, there are several other readings: chà, chāi, chài, cī, cuō, jiē.

2. Homonymy of words.

3. Tones that involve a large articular work.

4. Great semantic value of the tones - if the tone changes, the writing of the word hieroglyph and its meaning change dramatically. Very often, native speakers themselves during the speech clarify the meaning of a word depending on the tone.

The difficulties of the Russian language that were revealed during the second experiment. 1. Voiceless / voiced consonants at the end of the word: because of the fact that voiced consonants at the end of the word are devoiced, it is easy to make a mistake in writing (the Russian student made a mistake by writing not cinnamaldegiD, but cinnamaldegiT, it means 
that in oral speech she would incorrectly remember the term and would wrongly use it later, for example, she would then say "CinnamaldegiTa, cinnamaldegiTu", etc.).

The advantages of the Russian language that were revealed during the second experiment.

2. A higher average text reading speed -2 minutes 41 seconds, which is twice as large as Chinese, it proves that it is relatively easier to read in Russian.

3. The presence of the alphabet in contrast to the Chinese language, where the hieroglyphs are not systematized and their reading can only be memorized or checked in the dictionary.

Other currently important difficulties of the Chinese language, which were not revealed during the experiments, but exist depending on the situation. 1. There are 7 dialect groups in Chinese, which means that residents of different provinces often even can not support a conversation on everyday topics because dialects imply significant differences at the phonetic and lexical levels.

2. Traditional hieroglyphics, which is still used in the territory of Hong Kong, Macau, Taiwan and Singapore.

3. The presence of more than one hundred words in the Chinese language, which imply the use of a certain classifier after each numeral that refers to a particular noun. Sometimes native speakers find it difficult to use this or that counter word and that is why they use certain universal counter words.

4. Strong adaptation of proper names to their almost complete unrecognizability and dissimilarity in sounding with the original name. For example, names from the text 山本麻 由 Shānběn máyóu Mayu Yamamoto, 哈佛 Hāfó Harvard, etc ..

5. A huge number of words that have a large number of meanings based on the situation and context. This applies especially to verbs, for example, the verb 打 dă, which means "to hit, to beat," can be translated into Russian by many other words: 打杯子 break a glass, 打 鼓 hit / beat a drum, 打针 make an injection, etc. [3].

Other difficulties of the Russian language, which were not revealed during the experiments, but exist depending on the situation:

1. In the Russian language there is a large number of long terms, which are very difficult not only to use in speech, but even simply to write down. Let us give an example of several chemical terms that are extremely long:

- "Tetrahydropyranylcyclopentyltetrahydropyridopyridine" (55 letters, chemical substance).

- "Hydrazinocarbonylmethylbromphenyldihydrobenzdiazepine" (50 letters, tranquilizer Gidazepam).

- "Cocamidopropylpropyleneglycoldimmoniumchloridephosphate" (48 letters, chemical substance).

- "methoxychlorodiethylaminomethylbutylaminoacridine" (44 letters, chemical substance, another name - acrichine) [4].

2. In Russian, the word stress is very difficult. When the case and number are changing the stress can shift and it causes certain difficulties. In many languages the stress is almost always put on the last syllable (Turkish, Tatar), or on the first syllable (Czech, Latvian), or on the penultimate syllable (Polish). However in Russian there are no clear rules and the stress varies in different forms of the word. For example, golová-golovu-golóv-golovami (different forms of the word "head"). In a long word it can be somewhere at the very end, for example: pereraspredelenó (redistributed). The chemical word "výkristallizovavshiesya" (crystallized) is a perfectly correct Russian word with an initial stress [5].

3. A large number of polysemantic words, this is especially the case of nouns (and of Chinese verbs as it was mentioned above). For example, the word "order"", which was noted by one of the Chinese students participating in the experiment. If you look into the explanatory dictionary, you will see seven different meanings of the word: 1 . Well-organized state 2. Control system, structure 3. Lifestyle, way of life 4. Certain sequence, course 5. 
Military organization, formation. 6. Way, method 7. Variation, type of something 8. Conversation word for assessing the situation [6].

Table 1. Total calculation of all the advantages and disadvantages that were revealed during the experiment.

\begin{tabular}{|l|l|l|}
\hline & The Chinese language & The Russian language \\
\hline First experiment & Disadvantages 7 Advantages 2 & Disadvantages 4 Advantages 4 \\
\hline Second experiment & Disadvantages 4 Advantages 0 & Disadvantages 1 Advantages 2 \\
\hline Other cases & Disadvantages 5 Advantages 0 & Disadvantages 3 Advantages 0 \\
\hline Total & Disadvantages 16 Advantages 2 & Disadvantages 8 Advantages 6 \\
\hline
\end{tabular}

\section{Conclusion}

It is obvious that it is not possible to analyze and mention all the disadvantages and advantages of the Chinese and Russian languages as these language systems are rather complicated and extensive. However, the data that were collected during the experiments and theoretical knowledge allow us to see that the Russian language has more advantages that the Chinese language. Although grammatical categories of the Russian language are difficult to use [7], they nevertheless contribute to the most detailed description of a phenomenon, which is very important in the most specific areas of expertise, where it is necessary to describe every minor detail of what is happening, for example, during experiments on chemistry or surgical operations. The Chinese language is easier for understanding the meaning of individual words, but not of the whole sentence or a text. This is especially the case of any specialized terms in certain areas, for example, in chemistry [8]. The Russian language is harder for understanding technical terms, since most of the words were borrowed from Latin and Greek.

\section{References}

1. A. Piperski, Language Complexity, URL: https://postnauka.ru/video/54750 [in Russian]

2. A. Berdichevskiy, Language Complexity. Topics in the Study of Language, 5 (2012) [in Russian]

3. U. Lizhu, Young Scientist 7, 1012 (2015) [in Russian]

4. Interesting Russian Words, URL: https://orfogrammka.ru

5. A. A. Zaliznyak, About Russian accent, URL: http://elementy.ru/nauchnopopulyarnaya_biblioteka/432371/Iz_russkogo_udareniya [in Russian]

6. S. Ozhegov, Dictionary of Russian Language, URL: http://www.ozhegov.org [in Russian]

7. M. A. Kulkova, E. A. Denisova, Th. H. Zinecker, MJLTM 202 (2016) [in Russian]

8. T. A. Martseva, A. Yu. Snisar, Yu. V. Kobenko, K. A. Girfanova, International Conference on Linguistic and Cultural Studies 677, 266 (2018) 